\title{
Forecast diamond quality in the deposit
}

\author{
KriulinaG.Yu., Garanin V.K., \\ M.V. Lomonosov Moscow State University, Moscow, Russia; galinadiamond@gmail.com
}

Comparative analysis of diamond features and the host kimberlite rocks from the mines of Arkhangelsk and Yakutia diamond provinces enabled to establish the relationship between typomorphic groups of diamond and certain petrochemical type of kimberlite rocks. The most similar parameters have diamonds from the same field and same petrochemical type of kimberlite rocks. The kimberlite productiveness decreases depending on titanium oxide content in the rocks; with that the content of diamonds with high grade of nitrogen aggregation into the B-form and platelets concentration increases. The relationship between features and quality of diamonds and host rocks is understood.

INTRODUCTION

The diamond raw quality is determined upon the popular " $4 \mathrm{C}$ " system(carat, color, clarity, cut(habit)) base, descry these parameters from mineralogical and gemological view. Analyze the economic based deposit work off on the diamond quantity and quality knowledge base.

OBJECTS and INVESTIGATION METHODS

The research object is diamond raw probes from diamondbearing provinces: Arhangel (ADP, Arhangelskaya, Karpinskovo-1, n.a.Grib pipes) and Yakutsk (YDP, Botuobinskaya, Nyurbinskaya, Internationalnaya, Mir, Udachnaya, Yubileinaya, Komsomolskaya pipes). The diamond weight is from 0,15 until 1,00 ct. The investigations were held for the ten thousands diamond crystals.

The methods: optic and scanning electron microscopy (SEM), colored cathodoluminescence, optic spectroscopy in infrared (FTIR), ultraviolet and visible range, photoluminescence spectroscopy under xenon lamp light energization within 250-600 nm waves range and electron paramagnetic resonance (EPR).

The crystals infrared spectra registration are held with Furie spectrometer VERRTEX-

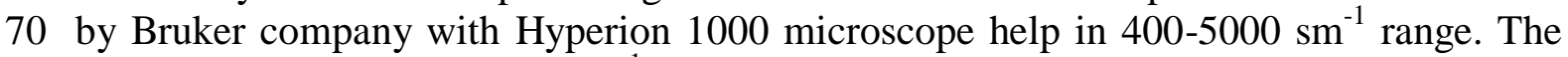
automatic program provides $2.8 \mathrm{sm}^{-1}$ spectrum split width. The absorbtion peaks re-count upon quantity content are held according [Boyd et al, 1994, 1995; Khachatryan, 2010]. The playlets $(\mathrm{P})$ and hydrogen centres relative content within diamonds is estimated according absorbtion band coefficients upon 1370-1365 and $3107 \mathrm{sm}^{-1}$. The $\mathrm{P}$ size is determined according band maximum position on 1370-1365 sm $\mathrm{sm}^{-1}$ [Kvaskov et al, 1997].

THE RESULTS AND THEIR DISCUSSION

The modern investigators (Bogatikov et al 2010; Vasilenko et al 1997 and others) prefer the $\mathrm{TiO}_{2}$ indicator role for marking kimberlite types, because its low content reflects high pressure during kimberlite origin [Garanin et al 2009]. The common classification based on dividing kimberlite unto three petrogeochemical types was suggested [Bogatikov et al 2010]:low-titanium $\left(\mathrm{TiO}_{2}<1.0\right.$ mas.\%) (LTT), medium-titanium $\left(1.0<\mathrm{TiO}_{2}<2.5\right.$ mas.\%) (MTT) and high-titanium $\left(\mathrm{TiO}_{2}>2.5\right.$ mas.\%).

COLOR. The LTT kimberlite diamonds are characterized by the most color spectrum and the more colored diamonds occurancy frequency with octahedron-dodecahedron habit. The yellow, grey,smoky-brown colored crystals are prevailed. It is important to emphasize that one can find the fancy colored samples:pink-violet, light blue,orange (red-brown), yellow. The colorless stones proportion is minimum (less than 10\%), together with slightly colored diamonds is amounted $20-25 \%$. The yellow crystals with different intensity dominate (30-54\%) [Zinchuk, Koptil, 2003; Kriulina et al, 2011]. Colorless and slightly colored 
overload (dominate) among octahedron and dodecahedron habit diamond crystals within MTT kimberlites (33-60\%). Yellow-colored samlples with noticible tone proportion is minor (9-19\%). Smoky-brown colored stones are widely spread with plastic deformation upon dislocation vanish mechanism [Synthesis of minerals, 2000].

HABIT. It is necessary in case diamond quantity estimation within pipe to take into consideration I type diamonds because they are potentially jewelry raw-stuff. Jewerly yellow rough cubic is rare. The I type diamonds are $77-88 \%$ within LTT kimberlites, except Internationalnaya pipe $98 \%$. The typomorphic characteristic Zolotitsskaya field diamonds is a cubic habit diamonds significant spreading. Existing to $10 \%$ coated diamond is typomorphic to the Nakinskii field pipes.

THE KIMBERLITE BODIES SHAPING. THE DEFECTIVE-ADMIXTURE DIAMOND CONTENT

The diamonds from each petrochemical types deposits, inspite of nitrogen gross content wide variation, are characterized by the close value $\% \mathrm{~B}$ and playlets. The defects transformation occurs at high temperature (in B and P) [Synthesis of minerals, 2000; Taylor, Milledge,1995] and are accompanied by diamond oxide dissolution which (diamond) was in maternal rocks before kimberlite source forming(shaping). The diamonds from low-titanium type kimberlites $\left(\mathrm{TIO}_{2}<1.0\right.$ mas.\%. LTT) and medium-titanium type $\left(1.0<\mathrm{TiO}_{2}<2.5\right.$ mas.\%. MTT) are detached into two area on diagram (pic.1). The infrared spectroscopy data were taken into consideration only from octahedron to dodecahedron habit crystals because they are dominate in all pipes that's why fully characterize the deposit.

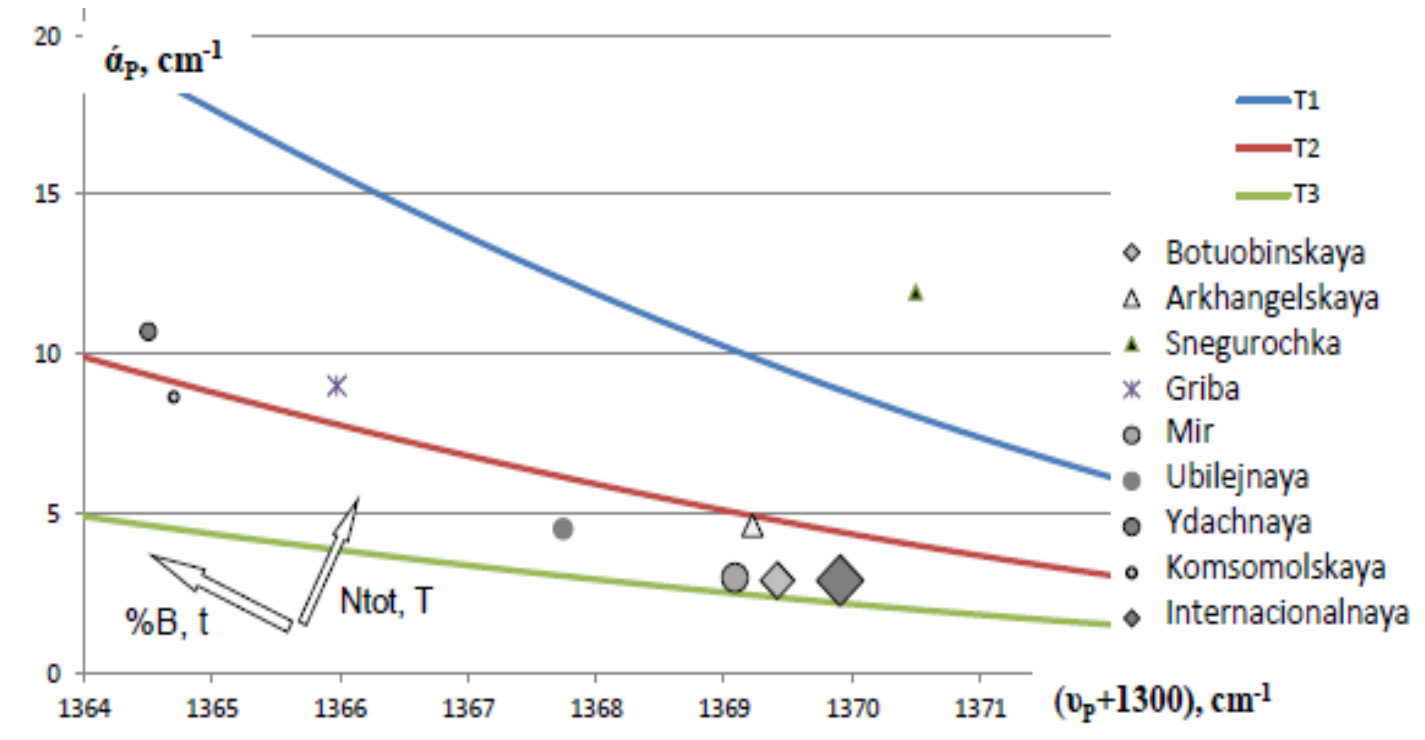

Pic.1. Diagram of diamonds from low-titanium type kimberlites $\left(\mathrm{TIO}_{2}<1.0\right.$ mas.\%.) and mediumtitanium type $\left(1.0<\mathrm{TiO}_{2}<2.5\right.$ mas.\%.) are detached into two area on diagram. $\mathrm{T} 1<\mathrm{T} 2<\mathrm{T} 3$.

The diamonds with the most playlets absorption coefficient which is in proportion to this defect content within crystal and the absorption band maximum position is in longwave range grew during the most high temperature conditions. They are the diamonds from Udachnaya, Komsomolskaya, n.a. Grib pipes. The crystals from Internationalnaya, Mir, Botuobinskaya. Arhangelskaya, n.a. Karpinskogo-1 grew in less temperature conditions. The epigenetic diamond evolution process is manifested in structure defects transformation, cryastalmorphology changing and sometimes colors, these procceses are connected to each other but can be detached.

CONCLUSION 
The kimberlite peridotite and eclogite enrichment most ancient calculated age correlate with short-lasting diamonds after crystallization annealing during which the defects transformation is possible, and low grade nitrogen defects aggregation. The pipes with the most ancient enrichment age are characterized by the certain diamonds morphogenetic groups prevelance depending on kimberlite type of rocks:nitrogenless and with high nitrogen for the LTT bodies [Kriulina et al, 2013]. The kimberlite bodies potential mantle diamonbearing is determined by phisic-chemistry criteria which suggested by Sobolev V.S., Sobolev N.V., Marakuchev and others.

One can forecast in pipes with low titanium content $\mathrm{TiO}_{2}<1$ mas.\% within kimberlite and enrichment age more than 1billion years [Bogatikov et al, 2010] the more diamond amount with yellowish nadre and tone. The pink-lilac, lilac (M2 defect) colored diamonds occurance possibility increase [Mineeva et al, 2007]. If the enrichment age is reduced until 0.6 billion years the colorless (with defects in complex A.B.P-forms) and smoky-brown stones (N2,W7 defects) is increased. During the longlasting elevation diamond material to the earth surface the conditions for its oxidation are created, i.e. the habit transformation into dodecahedron with weight loss until its full dissolving and recrystallization also and growth cubic and coated diamonds.

The real kimberlite productivity (i.e. the possible mantle diamondbearing decrease) depends on time of influence high-temperature mantle and the most low-temperature insidepipe metasomatic procceses. These proceses appear in kimberlite rocks matrix according diversity, spinel trend extention, the reaction minerals development, in diamond - according the nitrogen aggregation grade and curve-facets habits spreading.

By stydiing the kimberlite rocks petrochemical content, the oxide mineralization feature we can forecast kimberlite bodies diamondbearing and come close to undirect estimate the pay working off perspective with considering the diamond raw quality.

\section{References}

1. Bogatikov OA, Kovalenko VI, Sharkov EV Magmatism, tectonics, geodynamics of the Earth: connection in time and space M.: Nauka, 2010. 606p.

2. Boyd S. R., Kiflawi I., Woods G. S. The relationship between infrared absorption and the A defect concentration in diamond // Phil. Mag., B. 1994. V. 69. P. 1149-1153.

3. Boyd. S. R., Kiflawi I., Woods G. S. Infrared absorption by the B nitrogen aggregate in diamond // Phil. Mag., B. 1995. V. 72. P. 351-361.

4. Garanin VK Bovkun AV, Garanin KV, Rothman AYa., Serov IV. Microcrystalline oxides from kimberlites and related rocks of Russia. M.: MSU, 2009. 498 p.

5. Kvaskov VB, Vecherin PP Zhuravlyov V.V. Natural diamonds of Russia. M.: Polaron. 1997. 230 p.

6. Khachatryan G.K. Typification of diamonds from kimberlites and lamproites in the distribution of nitrogen centers in crystals // Ores and minerals, 2010. No. 2. P. 46-60.

7. Kriulina G.Yu, Garanin V.K., Rotman A.Ya, Koval'chuk O.E. (2011) Peculiarities of Diamonds from the Commercial Deposits of Russia// Moscow University Geology Bulletin, том 66, № 3, c. 171-183

8. Kriulina G.Yu, Garanin V.K., Samosorov G.G. Forecasting the quality of diamond in deposits of different petrochemical type. News of higher educational institutions. Geology and exploration. M. № 6.

9. Mineeva R.M., Speransky A.V., Titkov S.V., Zudin N.G. The ordered creation of paramagnetic defects at plastic deformation of natural diamonds // Physics and Chemistry of Minerals. 2007. V. 34. № 2. P. 53-58.

10. Synthesis of minerals. Tom.3 Aleksandrov: VNIISIMS, 2000. 345p.

11. Taylor W.R., Milledge H.J. Nitrogen aggregation character, thermal history and stable isotope composition of some xenolith-derived diamonds from Roberts Victor and Finch // Extended Abstr. of the 6-th Int. Kimberlite Conf. Novosibirsk, 1995. P. 620-622.

12. Vasilenko VB, Zinchuk NN, Kuznetsova LG Petrochemical models of diamond deposits in Yakutia. M.: Nauka, 1997. 575p.

13. Zinchuk NN, Koptil VI Typomorphism of diamonds of the Siberian platform. M.: OOO «NedraBisnescentre». 2003. 603 p. 